\title{
A Review of half-car model vibration system using Magneto rheological Dampers
}

\author{
Sumedh Marathe*, Swapnil Hatwalane, Sandeep Thorat and Nilesh Dhokane \\ Student of Mechanical Engineering Department, MITCOE, SPPU, Pune
}

Accepted 02 March 2016, Available online 15 March 2016, Special Issue-4 (March 2016)

\begin{abstract}
The suspension system is very crucial when considering the ride comfort of vehicle driver and passengers. Most of the research these days is based on the use of semi-active suspensions for vehicle suspension system. This system having a semi-active suspension with MR dampers is promising way of improving the ride comfort. This paper reviews the various ways of improving the ride comfort using various mathematical models, experimental work and gives an overall conclusion of why using a semi-active suspension system with MR dampers is better than using a passive system or an active system..
\end{abstract}

Keywords: Semi-active suspension system, MR dampers

\section{Introduction}

Vehicle seat suspension systems play a very vital role in driver's and passengers' comfort. The primary function of the suspension system of a vehicle is to isolate the vehicle body from the road loads and to provide favorable handling by maintaining the roadtire contact[Anria Strydom , Sudhir Kaul , 2012]. The suspension can be achieved either by passive suspension or using active or semi-active suspension. Passive suspensions make use of oil dampers which can be used as it is economical and simple. But the performance is not improved efficiently. Seat suspension system is required to perform its function at lower frequencies because the vibration energy is produced at lower frequencies (generally less than $10 \mathrm{~Hz}$ ). Active suspension provides high performance improvement at any range of frequencies but the design is complex and costly as it requires high power requirement, variety of sensors and servo valves. Semiactive vibration isolation is intermediate between active and passive. The drawbacks are eliminated by semi-active suspension system which provides comparable performance to active suspensions but without the high cost [H. Metered, p. Bonello, s. 0. Oyadiji,2009]. Semi-active devices like Magnetorheological Dampers can be used as they have the ability to provide adjustable damping. The fluid in these dampers has micron-sized magnetically polarizable particles suspended in a fluid with additives to take care of the settling, to enhance stability, improve lubrication and inhibit wear. These devices are preferable as the vehicle can generate voltage/current required to control the variable damping force. The voltage which the electromagnet receives can be directly controlled rather than the desired control force [Anria Strydom, Sudhir Kaul, 2012]. Hence, this suspension system is widely used for vehicle seat isolation. The potential application of MR damper in vehicle suspension system is reviewed.

\section{Need of work}

Vehicle suspension systems play a vital role in the comfort of the passengers. So, a lot of research is going on in the field of vehicle suspension to find an efficient and cost effective suspension system. It considers the isolation of vehicle seat from the road irregularities. From the 3 suspension systems viz. passive, semiactive and active , the semi-active suspension system is found to be cost efficient and effective. Hence, it is the most widely used suspension system.

\section{Mathematical Modeling}

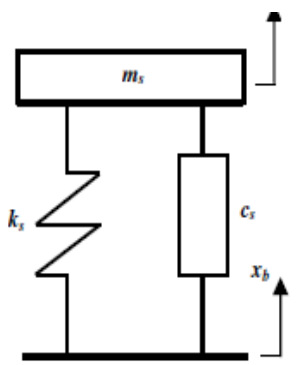

(a)

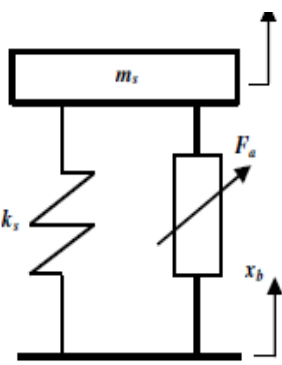

(b)
(a)Passive
(b) Semi-active

Fig.1 Vehicle seat suspension system 
Figure(1) shows passive and semi-active suspension models based on Single Degree Of Freedom (SDOF) The damper is represented by a controllable MR damper force, which is adopted in this study using the Modified Bouc-Wen model [H. Metered , p. Bonello, s. O. Oyadiji , 2009].

The governing equation of the motion of vehicle seat suspension is

$m_{s} x_{S}+k_{s}\left(x_{s}-x_{b}\right)+F=0$

where,

$$
\begin{array}{cr}
F=c_{s}\left(X_{s}-X_{b}\right) & \text { for passive suspension } \\
=\mathrm{F}_{\mathrm{a}} & \text { for semi-active suspension }
\end{array}
$$

A suspension system in which there is a small relative displacement has high sprung mass acceleration while large relative displacement is observed to have low sprung mass aceeleration. Hence, the control is achieved such that the MR damper is switched to a high damping ratio as the relative displacement is higher than a specific value and a low damping value otherwise[Y. SHEN , M. F. GOLNARAGHI , G. R. HEPPLER , 2005]. This control is given by -

$$
\begin{aligned}
\Gamma \mathrm{s} & =\Gamma_{\max } & & \left|\mathrm{x}_{\mathrm{s}}-\mathrm{y}\right| \geq \delta \\
& =\Gamma_{\min }=0 & & \left|\mathrm{x}_{\mathrm{s}}-\mathrm{y}\right|<\delta
\end{aligned}
$$

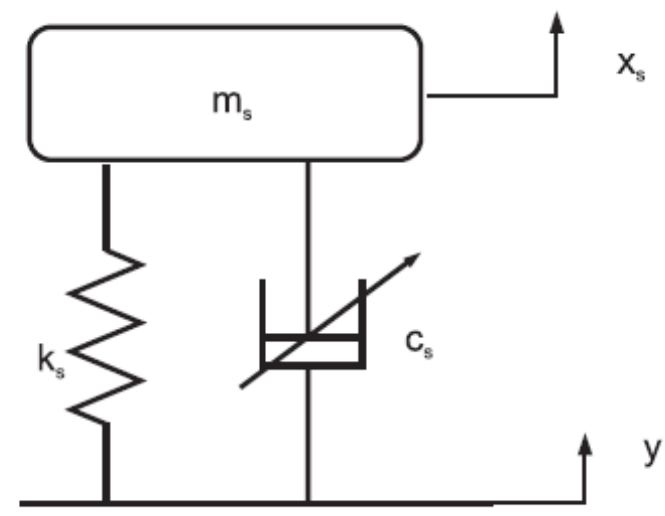

Fig.2 1DOF suspension system

According to skyhook working principle, the semiactive law for on-off control is -

$$
\begin{aligned}
\Gamma_{\mathrm{s}} & =\Gamma_{\max } & & \mathrm{x}_{\mathrm{S}}\left(\mathrm{x}_{\mathrm{S}}-\mathrm{y}\right) \geq 0 \\
& =0 & & \mathrm{x}_{\mathrm{s}}\left(\mathrm{x}_{\mathrm{S}}-\mathrm{y}\right)<0
\end{aligned}
$$

Figure(2) is a 2-DOF vehicle using a MR damper. The dynamics of the damper are modeled using Bingham model (the first model used to study the behaviour of MR damper][ R N Yerrawar, Dr.R.R.Arakerimath , Patil Sagar Rajendra, Walunj Prashant Sambhaji , 2014].

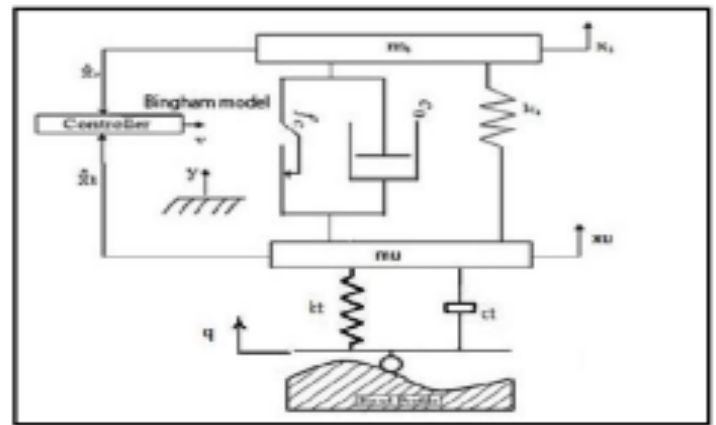

Fig.3 Car model with MR damper

The motion equations of the car body and wheel of this model are given as

$$
\begin{aligned}
& m_{s} x_{s}=-\left[k_{s}\left(x_{s}-x_{u}\right)+f_{a}\right] \\
& m_{u} x_{u}=-\left\{-\left[k_{s}\left(x_{s}-x_{u}\right)+f_{a}\right]+\left[k_{t}\left(x_{u}-q\right)+c_{t}\left(x_{u}-q\right)\right]\right\}
\end{aligned}
$$

\section{Semi-active control using MR dampers}

The following figure describes the block diagram of the semi-active suspension system using an MR damper [H. Metered , p. Bonello , s. O. Oyadiji , 2009]. The system has 2 nested controllers, one system controller and one damper controller. The system controller is used to calculate the desired damping force using the dynamic response of the seat suspension mathematical model. The damper controller adjusts the voltage applied to the damper so that it can track/compare the actual force to the desired force. The output of this damper is fed to the Modified Bouc-Wen model.

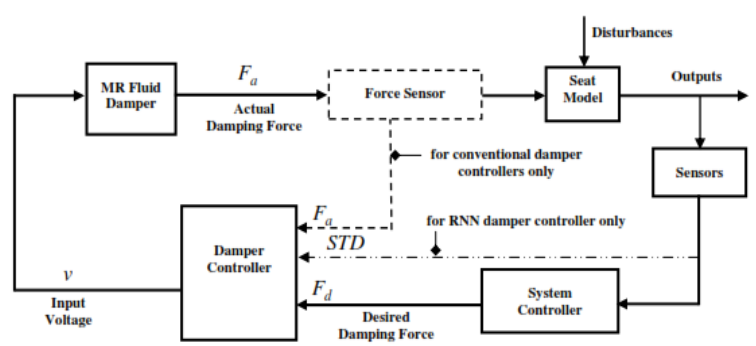

This figure shows the semi-active system for a vehicle seat in which an MR damper is used. The inverse RNN controlled dampers are preferred over the conventional control dampers because the conventional damper controllers need to be fed by calculating the actual force from a force sensor shown in the figure. This sensor is required to be connected in series with each MR damper which reduces the reliability and increases the cost. The inverse RNN damper controller measures the Seat Travel Displacement (STD) which is already available from the sensors used by the system controller.

\section{Experimental Work}

This setup is used to collect the data in order to build the BLS and LMS models [Anria Strydom , Sudhir Kaul , 2012]. 


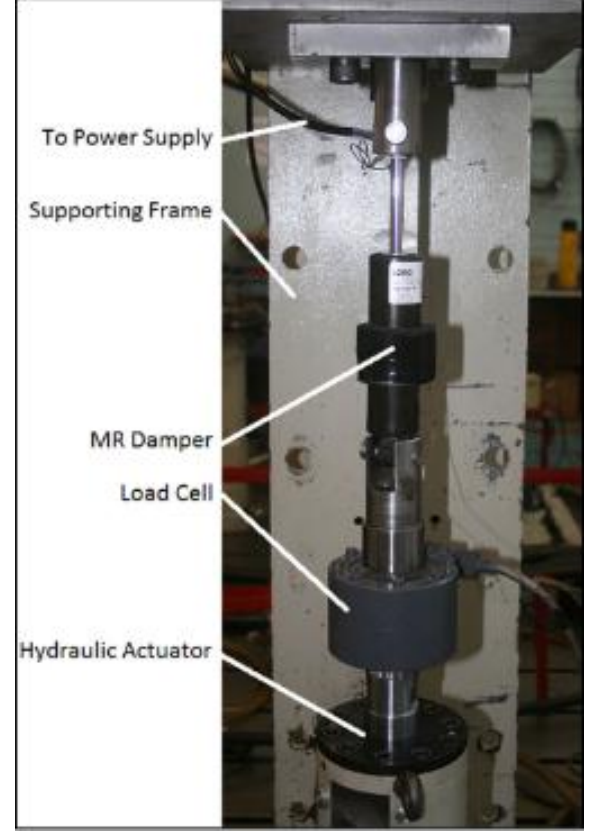

Fig.4 Damper characterization setup

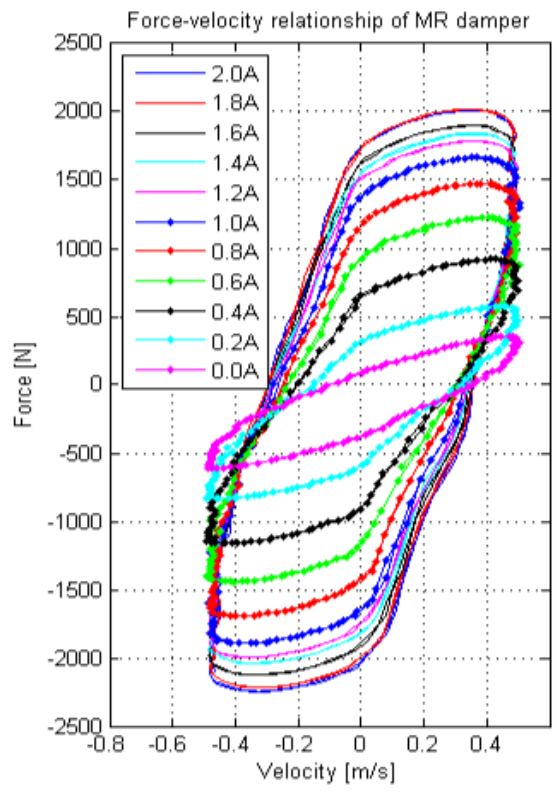

Fig.5 Measured data at $10 \mathrm{~mm}$ amplitude and $8 \mathrm{~Hz}$

The Root Mean Square (RMS) error is used to find out the accuracy of the models.

$$
\text { RMS Error }=\frac{\sqrt{\sum_{i=1}^{n}\left[\hat{f}_{i}(t)-f_{i}(t)\right]^{2}}}{n}
$$

The experimental work helps to determine the dependence of vibration isolation transfer coefficient of external vibration frequencies. The following figure shows the dependence of vibration isolation transfer coefficient of the frequency of external vibrations[Alexey m. Bazinenkov, valery p. Mikhailov , 2015].

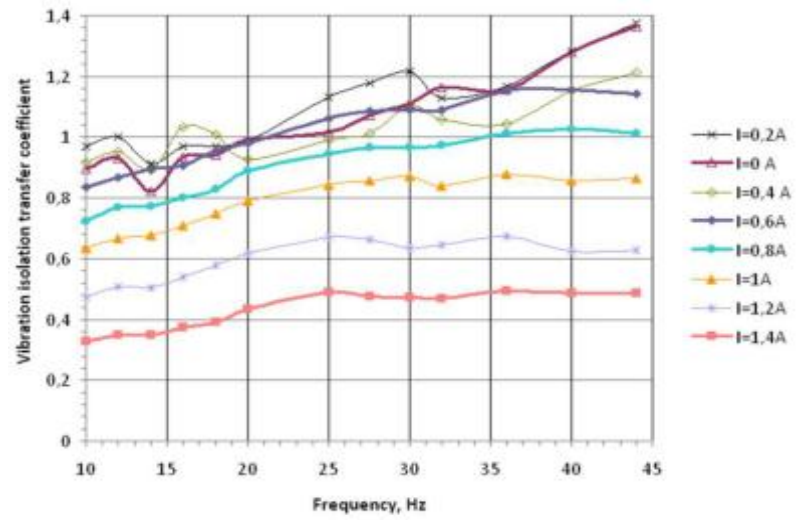

Fig.6 Experimental diagram of dependence of the vibration isolation transfer coefficient from the frequency of external vibrations

Figure 7 shows the suspension testing machine which is used to verify the efficacy of the various control methods.
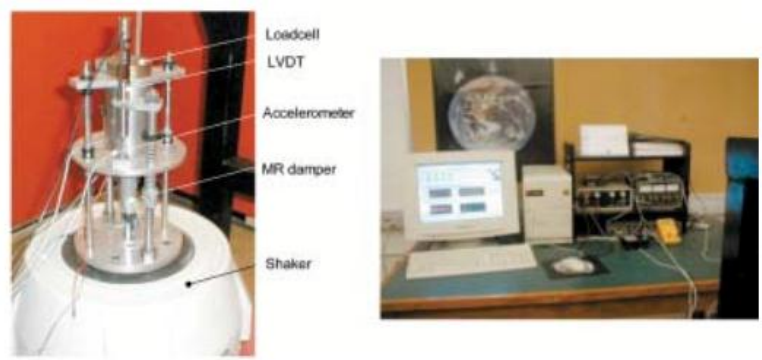

Fig.7 Car model suspension test rig

3 sensors are present to calculate the response of the system. A load cell is used to measure the damping force on the sprung mass , an LVDT is used to measure the relative displacement of the sprung mass and 2 accelerometers are used to measure the acceleration of the sprung mass and the base[Y. Shen, m. F. Golnaraghi, g. R. Heppler, 2005].

Figure 8 shows the test setup for measuring the time response and damping force of the magneto rheological damper.

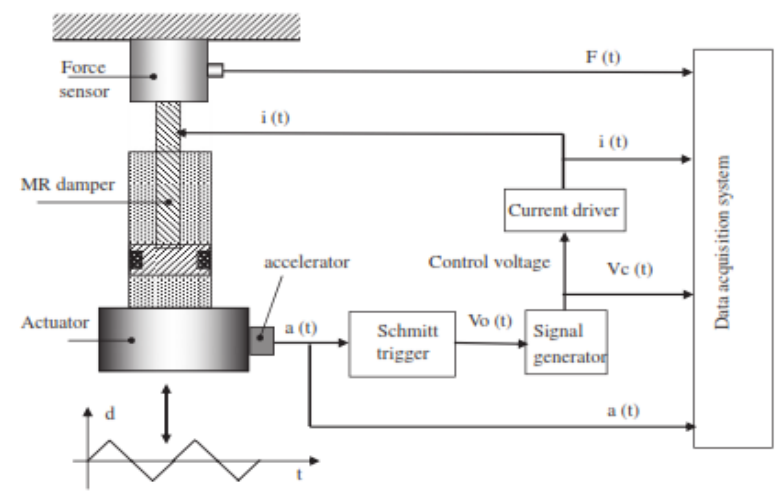

The damper is actuated by material test system frame. The force change due to the velocity makes the analysis 
complicated as we are only concerned with the change in force due to the control input.

The figures indicate the response of the step-up input and the step-down input [Miao Yua, , X.M.Donga, S.B.Choib, C.R.Liaoa , 2008].
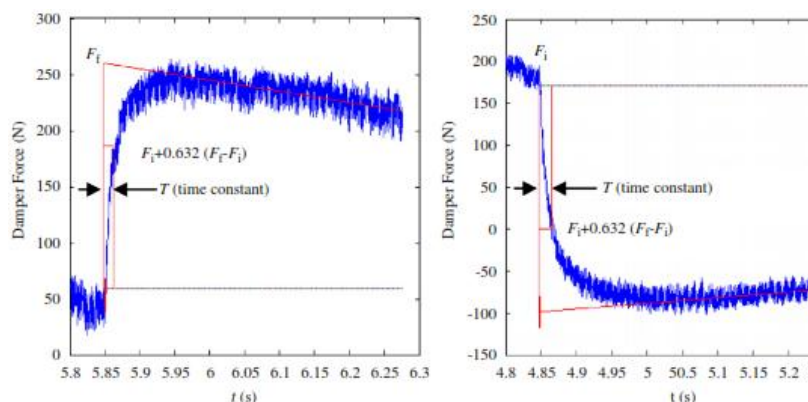

Fig.8 Time response of the damping force under step current input

Figure 9 shows the responses of MR dampers at frequency of $1 \mathrm{~Hz}$ for five constant electric currents. When the applied electric current is increased, the damping force increases considerably, but if the current exceeds $0.75 \mathrm{~A}$ then the change in the damping force is not significant[G.Z. Yao, f.f. Yap, g. Chen , w.h. Li , s.h. Yeo , 2001].
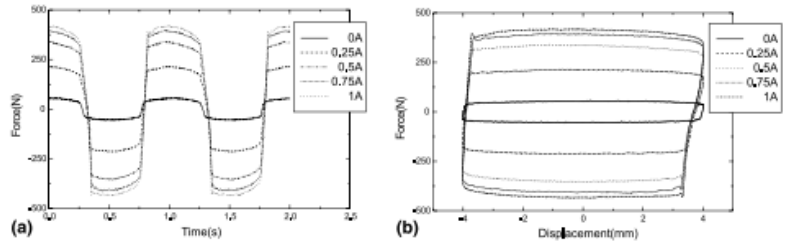

Fig.9 Comparison of estimated responses with corresponding experimental responses

\section{Conclusion}

The semi-active suspension system is reviewed and the following important conclusions are noted. The control methods viz. the R-S control and the MSK control method have more vibration control capabilities than by applying a constant current/voltage to the MR damper of the system. Hence, these control methods are preferred over the methods which use constant current/voltage. As the semi-active suspension system is able to vary its properties more freely than the passive suspension, it is being preferred over the passive suspension system. While studying the fundamental principles of the semi-active suspension system, several critical criteria such as weight, size , shape center of gravity, types of dynamic disturbances must be considered for proper result. If these important criteria are not considered, the design may fail or the system will not function properly. The preliminary simulation of the 2-degree-of-freedom model in which magnetically suspended vehicle is used showed that significant improvements related to the constant-damping linear suspension are possible using semi-active suspensions When compared to the seat suspension using the passive hydraulic dampers, the seat suspensions in which self-powered MR dampers are used reduced the values of the peak acceleration and RMS acceleration]. These values of peak and RMS acceleration are not reduced significantly in case of passive suspensions. The MR fluid dampers provide considerable scope to achieve better compensation of shock and vibration attenuation performance of suspension seats. It can be also seen that the power consumed by the controlled MR damper system is very much less than the system in which a constant voltage is provided]. The semi-active suspensions with new control strategies are more effective than the passive or semi-active suspensions with current neural network control]. These systems are developed by using Recurrent Neural Network (RNN) which increases the system reliability. The response of the vehicle which is modeled by the Modified Bouc-Wen model shows that the performance of the MR suspension can be improved by using the preview information and it is better than the performance of the passive suspension. If the variable damping coefficient is considered, the system which has a damping coefficient limit of $4000 \mathrm{~N} . \mathrm{s} / \mathrm{m}$ is the best when ride comfort is considered]. If the damping coefficient exceeds this value, it may reduce the ride comfort. The MR damper has a very large range of changeable damping force under the magnetic field and can be controlled by changing the applied voltage/current. Considering all these factors, the semi-active suspension system using MR dampers can be used for vehicle seat isolation as it is the most efficient and cost effective method and this provides the scope for further research.

\section{References}

Anria Strydom , Sudhir Kaul , (2012) , MR Damper modeling for semi-active control without force feedback, Proceedings of the ASME 2012 International Design Engineering Technical Conferences and Computers and Information in Engineering Conference IDETC/CIE 2012 August 12-15 , 2012, Chicago , IL , USA

H. Metered , p. Bonello, s. O. Oyadiji , (2009) , vibration control of a seat suspension system using magnetorheological damper Proceedings of the ASME 2009 International Design Engineering Technical Conferences \& Computers and Information in Engineering Conference IDETC/CIE 2009 August 30 - September 2, 2009, San Diego, California, USA

Alexey m. Bazinenkov, valery p. Mikhailov , (2015) , Active and semi active vibration isolation systems based on magnetorheological materials , Dynamics and Vibroacoustics of Machines , DVM2014 , pp. 170 - 174

Y. Shen , m. F. Golnaraghi , g. R. Heppler , (2005) , Semi-active Vibration Control Schemes for Suspension Systems Using Magnetorheological Dampers, Journal of Vibration and Control, 12(1) , pp. 3-24

R N Yerrawar, Dr.R.R.Arakerimath, Patil Sagar Rajendra, Walunj Prashant Sambhaji , (2014), Performance Comparison of Semi-Active Suspension and Active 
Suspension System Using MATLAB/ Simulink, International Journal of Innovative Research in Science, Engineering and Technology, Vol. 3, Issue 12, December 2014 , pp. 18293-18299

S J Dyke, B F Spencer Jr , M K Sain and J D Carlson , (1996), Modelling and control of MR dampers for seismic response reduction, pp. 1-19

Nader Jalili , (2002) , A Comparative Study and Analysis of Semi-Active Vibration-Control Systems , Journal of Vibration and Acoustics, Vol. 124 , pp. 593-605.

Jorge De Jesus Lozoya Santos , Ruben Morales Menendez And Ricardo A Ramirez Mendoza , (2012), Control of an Automotive Semi-Active Suspension, Tecnologico de Monterrey, Campus Monterrey, Monterrey, NL, Mexico , Volume 2012, Article ID 218106 , pp. 1-21

D. Hrovat , d. L. Margolis , m. Hubbard , (1988) , An Approach Toward the Optima

Semi-Active Suspension, Journal of Dynamic Systems, Measurement, and Control , Vol. 110 / 289 , pp. 288-296

Bo Huang , Chen-Yu Hsieh , Mehrdad Moallem , (2015) , A Methodology for Optimal Design of a Vehicle Suspension System With Energy Regeneration Capability , Journal of Vibration and Acoustics, Vol. 137 , pp. 051014-1-11

Miao Yua, , X.M.Donga, S.B.Choib, C.R.Liaoa , (2008) , Human simulated intelligent control of vehicle suspension system with MR dampers, Journal of Sound and Vibration 319 (2009) , pp.753-767

David Simon, Mehdi Ahmadian , (2001) , Vehicle Evaluation of the Performance of Magneto Rheological Dampers for heavy Truck Suspensions , Journal of Vibration and Acoustics , Vol. 123 , pp.365-375

Young-tai choi , hyun jeong song, norman m. Wereley, (2009) , semi-active isolation system using self-powered Magnetorheological Dampers, Proceedings of the ASME 2009 Conference on Smart Materials, Adaptive Structures and Intelligent Systems SMASIS2009 September September 21-23, 2009, Oxnard, California, USA , pp.1-10

S. J. Mcmanus and k. A. St. Clair , p. Ed . Boileau and j. Boutin , s. Rakheja , (2001), evaluation of vibration and shock attenuation performance of a suspension seat with a semiactive magnetorheological fluid damper, Journal of Sound and Vibration (2002) 253(1), pp.313-327
Douglas Ivers , Douglas Leroy , (2011) , Improving Vehicle Performance And Operator Ergonomics: Commercial Application Of Smart Materials And Systems , Proceedings of the ASME 2011 Conference on Smart Materials, Adaptive Structures and Intelligent Systems SMASIS2011 September 18-21, 2011, Scottsdale, Arizona, USA , pp.1-5

Alan Hiu-Fung Lam And Wei-Hsin Liao , (2003), Semi-active control of automotive suspension systems with MR dampers, International journal of vehicle design Vol.33 pp.50-75

Haiping Du , Kam Yim Sze , Jameslam , (2004) , Semi-active control of vehicle suspension with magneto-rheological dampers' Journal of Sound and Vibration 283 (2005), pp.981-996

D.L.Guo , H.Y.Hu , (2003) , Neural Network Control for a semiactive vehicle suspension with a MR damper, Journal of vibration and control pp.1-10

Herman a. Hamersma , p. Schalk els , (2014) , Improving the braking performance of a vehicle with ABS and a semiactive suspension system on a rough road, Journal of Terramechanics 56 (2014) , pp.91-101

R.S. prabakar, c. Sujatha, s. Narayanan , (2009), Optimal semi-active preview control response of a half car vehicle model with magnetorheological damper' Journal of Sound and Vibration 326 , pp.400-420

Abroon jamal qazi , afzal khan , m. Tahir khan , sahar noor (2013) , A Parametric Study on Performance of SemiActive Suspension

System with Variable Damping Coefficient Limit, 2013 AASRI Conference on Intelligent Systems and Control , pp.154159

Tomoaki Mori , Itthisek Nilkhamhang , Akira Sano , (2007) Adaptive semi-active control of suspension system with MR damper

Sy Dzung Nguyen, Quoc Hung Nguyen, Seung-Bok Choi , (2014) , A hybrid clustering based fuzzy structure for vibration control - Part 2: An application to semi-active vehicle seat-suspension system , Mechanical SystemsandSignalProcessing56-57(2015) , pp.288-301

G.z. Yao , f.f. Yap, g. Chen , w.h. Li , s.h. Yeo , (2001) , MR damper and its application for semi-active control of vehicle suspension system, Mechatronics 12 (2002), pp.963-973 